\title{
Perceived Availability, Risks, and Benefits of Gambling among College Students
}

\author{
Emerson M. Wickwire Jr. · James P. Whelan · Rebecca West · \\ Andrew Meyers · Claudia McCausland · Jason Luellen
}

\section{Erratum to: J Gambl Stud DOI 10.1007/s10899-007-9057-5}

The correct spelling of the last coauthor's surname is "Luellen".

The online version of the original article can be found under doi:10.1007/s10899-007-9057-5.

E. M. Wickwire Jr. · J. P. Whelan $(\bowtie) \cdot$ R. West · A. Meyers · C. McCausland · J. Luellen The University of Memphis, 202 Psychology, Memphis, TN 38138-3230, USA

e-mail: jwhelan@memphis.edu

Present Address:

E. M. Wickwire Jr.

Psychology Department, The University of Mississippi Medical Center, 2500 North State Street, Jackson, MS 39216, USA 